\title{
BEBER COMO HOMEM: \\ Dilemas e armadilhas em etnografias sobre gênero e masculinidades
}

\section{Pedro Nascimento}

Universidade Federal da Paraíba (UFPb), João Pessoa - PB, Brasil. E-mail: pedrofgn@uol.com.br

DOI: http//dx.doi.org/10.17666/319057-70/2016

\section{Introdução, ou aperitivo}

Este artigo foi construído sobre pesquisas realizadas em diferentes momentos (cf. Nascimento, 1995, 1999, 2000) e diálogos com diferentes interlocutores, a partir dos quais as reflexões aqui expostas foram se configurando. O eixo dessas reflexões é o fato de serem pesquisas interessadas em compreender a dimensão de gênero na forma como se apresenta no cotidiano de homens de classes populares, tendo o espaço dos bares como um ambiente sempre presente e a marca do consumo de bebida alcoólica no agenciamento de relaçóes, lugares e pertencimentos.

Minha interpretação se insere no âmbito dos estudos que, de acordo com a observação de Delma Pessanha Neves, caracterizam-se pela forma como a antropologia tem tratado a questão do consumo de

Artigo recebido em 12/11/2013

Aprovado em 26/08/2015 bebidas alcoólicas e o alcoolismo. Ou seja, evitando a relação com visões moralizantes e buscando a forma como os próprios sujeitos se classificam: "o ato social de ingestão da bebida alcoólica não pode ser estudado sem que sejam levados em consideração os sistemas de crenças no controle do comportamento e da socialização" (Neves, 2004, p. 9). Ainda nessa direção, interessa-me mais a compreensão dos modos como as pessoas se relacionam com o consumo de bebidas alcoólicas, a embriaguez e o alcoolismo, e não o por$q u \hat{e}$. Mais que uma fuga ao enfrentamento das questôes relacionadas ao "uso problemático" da bebida, esta opção reflete o interesse de contribuir para estudos que considerem as dimensões sociais desse uso e menos o "alcoolismo como patologia médico-social" (Neves, 2003, p. 79), sem negar a relevância dos estudos que consideram a relação entre ciência, poder e autoridade na produção de conceitos como dependência e adição (Berridge, 1994, p. 15). Ainda, por se tratarem de reflexôes surgidas no âmbito de pes- 
quisas que relacionavam gênero, sociabilidade masculina e trabalho, o exercício aqui é também de fugir à equação simples entre pobreza, precariedade e alcoolismo (Neves, 2004, p. 11).

Tais questões, não previstas inicialmente, foram surgindo e se construindo para mim, inserido no processo da pesquisa. Aos poucos, busquei caminhos para dar sentido aos questionamentos que se colocavam - a partir da centralidade da questão da bebida alcoólica - e pareciam não ter respostas fáceis. Nesse sentido, a reflexão sobre o ofício de etnógrafo em suas várias dimensões é outro elemento central nas reflexões que trago aqui. As dificuldades em campo para dar sentido às experiências dos sujeitos com quem convivi e os dilemas pessoais e éticos nessa trajetória são igualmente importantes para a elaboração do argumento. Deste ponto de vista, a experiência da etnografia está muito distante da visão do etnógrafo herói e sem dilemas que sabe muito bem quais as questóes que importam e a forma como "obtê-las". Assumo a postura de quem está construindo sentidos a partir das várias falas no sentido dado por Geertz (1989), que ultrapassa os limites do discurso oferecido ao investigador e considera as práticas sociais, os contextos, os fluxos de comportamento e as relações travadas, incluindo aquelas entre o pesquisador e seus interlocutores.

Concordando com a ideia de que "não existe método sem calcanhar-de-aquiles", busco não deixar que as possíveis fragilidades identificadas levem a uma paralisia, mas permitam explorar ao máximo as vantagens da escolha pela etnografia (Fonseca, 2000, p. 11). As dúvidas, imprevistos, mudanças de percurso passam, assim, a constituir elementos igualmente importantes, não apenas enquanto alegoria, mas "dados" a serem "analisados". Ao mesmo tempo, os diferentes lugares de onde meu olhar se constrói fazem-me considerar os diferentes vieses que, na trajetória de pesquisa, se insinuam e demandam serem considerados e os dilemas daí advindos. Dessa forma, este trabalho se insere em um conjunto de reflexões desenvolvido nas últimas décadas na antropologia, onde, ao problematizar o desenvolvimento da etnografia, são destacadas as relações entre pesquisador e interlocutores e suas implicações no processo de escrita etnográfica (Clifford, 1998; Geertz, 2002; Favret-Saada, 2005; Bonetti e Fleischer, 2007).

\section{Bar, bebida e gênero: buscando conexóes}

No Brasil, estudos em contextos diferentes têm refletido sobre a bebida como ato social a partir dos espaços dos bares (Machado da Silva, 1978), e alguns deles têm refletido sobre a relação entre o consumo de bebida alcoólica e a sociabilidade masculina, como certo aprendizado de códigos de masculinidade (Jardim, 1991; Guedes, 1997; Matos, 2001; Garcia, 2004). Para essa relação, vale destacar também pesquisas realizadas no México, a exemplo de Matthew Gutmann (1996) e Stanley Brandes (2003), apostando na possibilidade de aproximar este debate do campo de estudos sobre gênero e masculinidades. ${ }^{1}$ Ao mesmo tempo, Gutmann (1996) adverte para o fato de que dizer que há maior consumo de álcool entre os homens é diferente de pressupor um padrão de como os homens se relacionam com a bebida. Para a flexibilização dessa ideia, o autor usa a noção de degendering, significando que, embora os homens continuem bebendo mais que as mulheres, observa-se (para o caso do México) uma mudança no sentido de maior participação das mulheres, de forma que não se pode falar da bebida como algo "tipicamente masculino" a princípio.

$\mathrm{Na}$ mesma direção do que foi apontado por Neves (2003), Gutmann e Brandes, para o México, Simoni Guedes (1997, pp. 149-150), para o Brasil, reconhece a relação entre o consumo festivo e "naturalizado" de bebida com o alcoolismo, mas alerta para que o estudo do primeiro não deve estar subsumido ao segundo. Nesse sentido, quando estou falando muitas vezes em consumo de bebida alcoólica e alcoolismo ao mesmo tempo, não pretendo fazer uma confusão ou uma indiferenciação grosseira de duas realidades. Busco perceber que meus interlocutores, em momentos diferenciados, tratam essas duas realidades como coisas distintas, reconhecendo os malefícios do "beber em excesso", sem negar os aspectos de positividade do "beber junto". Trata-se, por outro lado, de perceber que o beber qualificado como excessivo "não pode ser compreendido apenas pela perspectiva da doença e do desvio. E, mesmo sob esta perspectiva, não pode ser compreendido tão somente pelo ato individual" (Neves, 2003, p. 83). Visa-se, com essa percepção, a substituição de uma perspectiva baseada na premissa de que o alcoolismo 
reflete "problemas de psicologias individuais", o qual se constituiria num problema para a sociedade, por uma perspectiva que vê o alcoolismo como criado socialmente e definido como um problema $d a$ sociedade (Gutmann, 1996, p. 174).

Assim, dialogarei com interpretações nativas que transitam desde uma consideração corriqueira e festiva da vida cotidiana regada a cachaça ou cerveja, a ponderações, juízos e "diagnósticos" a respeito de pessoas que têm um problema de saúde a ser resolvido. São percebidos limites tênues entre doença e "pouca vergonha" ou "vadiagem", e uma oscilação nas imagens manipuladas não só pelos que bebem e são assim enquadrados.

Embora concordando com Gutmann acerca do perigo de equacionar de forma naturalizada masculinidades e álcool, é nesse sentido específico que afirmo que, nos contextos por mim investigados, beber não apenas é algo presente como esperado, particularmente, nas trajetórias masculinas. Muitas vezes, beber masculiniza. Assim como dizer para os amigos que teve muitas relaçôes sexuais é uma forma de se apresentar como "mais homem", beber e, em alguns casos, beber muito, pode ser também uma forma de parecer do mesmo modo. Não será casualidade que entre os sujeitos investigados, apenas uma mulher foi identificada bebendo com regularidade em público, junto aos homens e embriagando-se. Não apenas no sentido da valorização do ato de beber, mas a legitimidade de beber em público e embriagar-se é um atributo masculino para as pessoas com quem convivi. ${ }^{2}$

Tais observações querem alertar para que, no caso da reflexão sobre a bebida em sua relação com os discursos sobre o trabalho, não é possível defini-la de modo determinante e com vias predefinidas de forma unicausal. Ou seja, não considerei casos de homens que deixaram de trabalhar por causa da bebida simplesmente, tampouco propus tratar de situações onde, por causa da falta de trabalho, os homens começaram a beber. Trata-se de um fenômeno mais complexo do que fazem supor algumas narrativas bastante difundidas e com personagens definidos mais ou menos como segue: certo dia um homem que perdeu o emprego ou a mulher ou algo muito significativo em sua vida (o teor psicanalítico do silogismo não retira sua popularidade) passou a beber de modo desregrado, acabando por perder o controle sobre sua ação. Esse "mito de origem" do alcoolismo, por si, não serve como explicação para as situações por mim encontradas.

Outro modo de explicação não menos difundido, e igualmente insuficiente, é o de que sujeitos irresponsáveis acabam perdendo repetidos empregos em decorrência de embriaguez, falta ao trabalho etc. Reconheço que ambas as explicações podem ser encontradas entre os homens que estudei. Mas quero chamar a atenção para o fato de que a presença do álcool na vida dos homens como algo corriqueiro e legítimo faz com que essa relação necessite ser analisada de modo mais cuidadoso, permitindo a percepção de que pode haver mais que dois caminhos para interpretá-la.

\section{Da etnografia nos bares: a festa e o sofrimento}

Conforme indiquei na introdução a este artigo, as questôes aqui trabalhadas surgiram em diferentes momentos de pesquisas distintas. Vou contar agora uma pequena história de como o cruzamento da questão dos bares enquanto "palcos de masculinidade" com o tema do "consumo excessivo" de álcool ou do alcoolismo foi se constituindo em uma questão para mim, com o objetivo de indicar minhas dificuldades para enfrentar certos dilemas em campo. Nem sempre estiveram muito claras essas questôes e algumas vezes necessitei de tempo e da interlocução com pessoas distanciadas desse processo para entender o que se me apresentava como novidade. Espero com isso exemplificar como o processo de construção de nossas questões de pesquisa e nossas escolhas e decisões em campo são muito mais complexas e, algumas vezes, mais complicadas do que supomos em um primeiro momento.

A questão da importância da sociabilidade dos bares para pensar a identidade masculina me foi colocada de modo mais claro quando realizei uma etnografia de um bar na feira central da cidade de Campina Grande, Paraíba. O meu lugar é o de alguém que iniciou seu exercício de etnógrafo a partir desses espaços. Este bar se caracterizava principalmente por ser frequentado, em sua maioria, por homens das classes populares que estavam de alguma forma relacionados ao trabalho na feira livre. Ao longo da investigação, o bar foi se configurando enquanto um espaço profícuo 
para a reflexão sobre a sociabilidade masculina e a negociação de suas identidades. Este funcionava como um grande fórum de discussão e cenário para o relato de experiências. Entre os muitos assuntos partilhados, o sexo era a temática recorrente. Embora ausente fisicamente, a mulher era o pano de fundo das conversas que giravam em torno de três assuntos: a infidelidade feminina, enunciada no medo de ser "corno"; a potência sexual, torneios sexuais verbais acerca do maior número possível de relações sexuais; e a homossexualidade (Nascimento, 1995).

Alguns anos depois, no mestrado em antropologia na Universidade Federal de Pernambuco, realizei uma segunda pesquisa em Camaragibe, na Região Metropolitana do Recife, Pernambuco, buscando entender a diversidade de experiências masculinas para aquele grupo (Nascimento, 1999). Neste contexto onde muitas das características percebidas coincidiam com as identificadas no contexto anterior, os bares se apresentavam como espaços de sociabilidade masculina, onde determinados repertórios eram quotidianamente atualizados (Almeida, 1995; Nascimento, 1995, 1999), conformando-se em cenários onde se aprendia a "ser entre homens", numa escolha pela autossegregação, a qual aponta para a "importância da troca de experiências entre homens na elaboração de uma cultura masculina” (Jardim, 1991, pp. 127-129). Por sua característica de informalidade, percebi aquele bar como permitindo a problematização de alguns elementos, ao favorecer aos homens a emersão dos sentimentos e a visualização de suas fragilidades, em grande medida, viabilizadas pelo consumo de álcool. Do mesmo modo, o fato de colocar homens distintos, sob vários pontos de vista, segregados das mulheres em um mesmo espaço, fazia com que se visualizassem as assimetrias internas à masculinidade, apresentando o bar não apenas em sua dimensão lúdica e festiva, mas também de enfrentamentos e tensões. Ao mesmo tempo que se dá apoio, ouvido e força, no bar há também provocação, humilhação e acusação, como apontam minhas notas de campo de 1999 em Camaragibe:

Estávamos eu, Jota, Beto, Brito, Antônio ${ }^{3}$ e outros que ainda não conhecia, sentados na calçada, em frente ao bar do Bosco, o preferido da grande maioria deles. Renato (cerca de 43 anos), já um tanto trôpego, passa em frente ao bar chamando palavrōes. Marcelo, o dono do bar vizinho, reclama mandando-o parar. Todos os que estavam na calçada, aproveitam o ensejo, entendo eu que, menos para apoiar o dono do bar que para provocar Renato, o bêbado: "É isso mesmo. Olha o palavrão! A mulher de Marcelo tá aî". E das reclamaçôes passa-se a uma grande algazarra marcada por gritos e xingamentos dirigidos a Renato que ameaça jogar-lhes pedras. A esta ameaça, os que estavam provocando mais diretamente, correm para se livrarem das possíveis pedradas. Ao mesmo tempo, quando Renato se senta em frente a uma casa vizinha, começam a chamá-lo por "Traguinho" e "Corno". Sempre com alguém se escondendo por detrás de alguém, em voz alta, provocavam: "Vamos tomar um traguinho!". [Eu não teria entendido a razão porque Renato, a cada vez que ouvia a palavra traguinho, mais se enfurecia, se não tivesse sabido pouco dias antes seu pequeno segredo: Traguinho era o apelido do homem com quem sua esposa tinha vivido por alguns anos. "O mais grave", haviam-me dito, foi que, após ela separar de Traguinho, Renato a havia "aceitado de volta"]. Nisso, Renato esbravejando de modo incompreensível, dirige-se apressadamente pelo beco sem calçamento em direção a sua casa. "Ele ainda vai voltar. Deve ter ido buscar a faca em casa", comentam os que ainda estavam na calçada comigo. Advertem uns aos outros que ele deverá voltar por um lugar diferente do que foi. Esperam uma "emboscada". Ao mesmo tempo, dizem que ele não tem coragem de ferir ninguém e que seria fácil desarmá-lo apenas "botando bocão". Em meio a essa conversa, chega um senhor querendo saber o que tinha acontecido a Renato, pois o havia encontrado muito nervoso, perguntando se teria um revólver para lhe emprestar, pois queria "dar um tiro num cabra safado". Pouco depois, Renato chega com uma faca de cozinha sem bainha acomodada por baixo do calção. Procurava Beto, um dos que estavam lá e havia sido o que mais o chamara de "Traguinho", mas este já havia ido embora. Entre outras bravatas, arremata, empunhando a faca: "Ele pensa que só ele é homem, mas eu vou mostrar que também 
sou homem". A plateia o assiste, rindo. Uns, dissimuladamente, outros, abertamente. Suas bravatas que se perdem na rua, agora já escura, soaram-me como as de um homem ferido. Bêbado e humilhado pela brincadeira dos amigos com os quais estará bebendo na sequência: "Vai tomar a tua, Renato. Tá lá no balcão!", diz Antônio, um de seus companheiros de copo que participara da cena. Ele se dirige ao bar, já bem mais calmo.

Não é apenas em relação ao outro ausente - a mulher - que o homem se diferencia e identifica, mas entre os próprios homens há códigos que definem o que é ser mais ou menos homem (Almeida, 1995 , p. 163). Penso o bar enquanto palco, na medida em que os homens encontram aí um espaço para certa performance da masculinidade (Jardim, 1991), o qual se constitui num processo social frágil, autovigiado e disputado (Almeida, 1995; Leal e Boff, 1996), interpretação para a qual a noção de performatividade do gênero é central (Butler, 2003). No bar se delimitam que conversas, posturas e atitudes podem informar sobre o que é ser homem, bem como manter-se assim. ${ }^{4}$

No momento em que finalizava a pesquisa para o mestrado, iniciei outro estudo onde havia definido como população a ser investigada homens desempregados. ${ }^{5}$ Não me interessavam os casos de homens que, desempregados, estavam à procura de trabalho, tendo sua história laboral caracterizada por períodos regulares de desemprego. Meu objetivo agora era caracterizar a condição de homens que apresentaram essa trajetória, mas, no momento da pesquisa, identificavam-se e eram identificados como estando em uma situação em que não mais buscavam superar esses períodos de desemprego, como era o caso de muitos com os quais eu havia convivido. Estes estavam em uma situação em que se identificavam e eram identificados como sendo homens que não trabalhavam e eram sustentados por outra pessoa.

Estava presente aí também o pressuposto que orientara minha investigação anterior (Nascimento, 1999), e que era partilhado por outros pesquisadores em diferentes contextos (Almeida, 1995; Connell, 1997, Valdés e Olavarría, 1998), da existência de certo modelo de masculinidade, segundo o qual o homem tem autoridade, sobretudo no lar; é autônomo e livre diante de outros homens; tem força e coragem e não expressa suas emoções, tampouco chora; é heterossexual e é o provedor do lar. Esta última característica sendo apresentada como central (Zaluar, 1985; Scott, 1990; Sarti, 1996), daí sua escolha para ser problematizada na nova investigação. ${ }^{6}$ É particularmente neste momento que os dilemas postos pelo exercício da etnografia, conforme anunciado anteriormente, começam a se fazer presentes de forma mais direta.

\section{Do bar para a casa; da casa para o bar: um insistente retorno}

A opção de trabalhar com os homens adaptados à condição de "não provedores" e "não trabalhadores" levou-me a princípio a uma busca pelos espaços em que estes pudessem ser localizados para além dos bares. Essa opção gerou algumas dificuldades na condução da investigação a princípio. Como muitos dos contatos que mantivera inicialmente se deram a partir do espaço dos bares, quando retornei para a realização da nova pesquisa, voltei a me relacionar com um número significativo de sujeitos com os quais estava habituado a conversar nos bares ou nas calçadas e rodas de jogos.

As novas questôes postas para a pesquisa implicavam necessariamente em que eu, sem perder os contatos estabelecidos e as relaçóes travadas, fosse capaz de ampliar o raio de convivência em que estava inserido. No sentido mais imediato, criar novos espaços, para mim, implicava poder ter acesso mais sistemático às casas desses mesmos sujeitos. Daí dois problemas se apresentaram.

Em um primeiro momento, eram esses mesmos sujeitos que se recusavam ou ao menos não tinham demonstrado disposição suficiente para partilhar comigo do universo de suas casas. Embora eu já tivesse ido à residência de alguns deles, isso não implicava convivência e circulação tranquilas, mas apenas no fato de que eles me haviam apresentado suas casas e alguns membros de suas famílias. Alguns até sempre diziam quererem me levar até suas casas, mas relutavam quando a questão era recolocada por mim. Enfim, conhecer suas moradias e ter ido até lá, não significava o mesmo que poder 
conviver com eles neste espaço - da casa - com a mesma facilidade com que o fazia nos espaços de homossociabilidade masculina. A este ponto está ligado o segundo problema a que me referia.

Em grande medida, essa dificuldade se deu pelo fato de que as pessoas que moravam na mesma casa que esses sujeitos me viam, em geral, como um de seus parceiros de bebida, o que fazia com que eu fosse recebido, às vezes com desatenção e outras vezes com desconfiança. Desatenção parece-me porque, assim como são pouco levados a sério esses homens, também seriam seus amigos. Desconfiança no sentido de que, apesar da associação, eu era visto como rico ou, quem sabe, um bobo que, algumas vezes, pagava bebida para os outros. E ainda é possível pensar que desconfiassem que eu tivesse "outros" interesses por seus homens, como me relatou Valdonilson Barbosa, então meu assistente de pesquisa, quando foi entrevistar Célia, esposa de Nino. Valdonilson explicou-lhe que ele participava da mesma pesquisa que eu, razão pela qual eu havia ido à casa dela antes procurando por seu marido, ao que a mulher comentou: "Eu achava que ele tava afim de Nino... veio aqui não sei quantas vezes procurá-lo...”.

A minha compreensão era de que já havia conseguido compor com as experiências anteriores de pesquisa nessa área um mapeamento suficientemente rico do que poderia chamar de o discurso público da masculinidade. Dessa forma, passei a buscar construir um panorama mais próximo da vida íntima desses sujeitos, intimidade aqui pensada apenas como proximidade da vida doméstica. No entanto, mesmo quando percebi que esses dois problemas de ordem mais prática seriam contornados, as dificuldades postas pela escolha feita nessa investigação não pareceram se esclarecer com facilidade.

Por várias vezes, mesmo insistindo na frequência às casas e na fuga dos bares, via-me sempre conduzido até estes ou às suas imediações. Seja porque, quando procurava os homens em suas casas, alguém dizia para procurá-los nos bares, seja porque esses mesmos homens me chamavam para ir até lá, mesmo quando não estavam bebendo. Isto porque era nos bares que encontrariam seus companheiros.

Não compreendia com muita clareza, a princípio, esse insistente retorno, percebendo-o às vezes como vício da experiência anterior de campo. Ficava incomodado por me perceber nos espaços informais, pretensamente tão conhecidos por mim, quando desejava estar participando mais da vida doméstica ou, ao menos, dos espaços que excediam aos bares. Contudo, esse retorno apresentava alguns elementos novos. Na primeira experiência, havia me detido, sobretudo, na dimensão lúdica do bar e sua possibilidade de oferecer um espaço onde se pode dramatizar com cores diversas os aspectos negativos do cotidiano daqueles homens. Agora estava sendo possível acompanhar mais de perto o lado menos festivo da vida daqueles que bebiam diariamente.

Passou a me chamar a atenção o quadro de homens embriagados nas primeiras horas do dia. Encontrava com regularidade, por volta de oito horas da manhã, homens já caídos nas calçadas e nas ruas. Alguns deles já haviam começado a beber desde a madrugada, pois levavam bebida para casa para que a tomassem ao acordar. Outros me pediam dinheiro para comprar mais bebida. Antes, eu pagava bebida para eles nos bares sem maiores dilemas, pois me via inserido num circuito de reciprocidades e numa etiqueta do bar onde este era um dos requisitos. Agora, em situações como esta, passei a me recusar a pagar bebida, dando diferentes desculpas. Em outras situações ainda, alguns homens começavam a narrar sua trajetória, lamentando sua condição e buscando justificativas para a mesma.

Não estou dizendo que havia até então entendido a festividade nos bares como sendo a única dimensão relevante dessa vivência. Até tinha acompanhado também as desventuras de alguns daqueles homens, mas, neste momento, a realidade de sofrimento se apresentava de forma mais crua e seus efeitos sobre mim foram mais intensos. Desse modo, pensava mesmo que não conseguiria dar continuidade à pesquisa se não fosse possível criar outros espaços de investigação.

Em uma primeira análise, elaborei de modo problemático (o que só percebi depois), uma interpretação que orientou meu olhar em campo e pode ter adiado a percepção de outras nuanças. Entendia esse quadro como demonstrando que aqueles homens, estando impossibilitados de cumprirem com a prerrogativa do trabalho e do provimento do lar, não conseguiam redefinir o ambiente doméstico, 
eminentemente feminino, nem criar novos sentidos para as suas vidas. Sendo assim, o universo da bebida apresentava-se como a única possibilidade uma espécie de alternativa masculina diante da exclusão do espaço doméstico. ${ }^{7}$

Esta hipótese trazia uma dimensão por demais paralisante. Sendo assim, tal visão precisou dar lugar a uma busca dos possíveis sentidos da condição daqueles homens para que, inclusive, permitisse não constituir uma tendência à sua vitimização. Sabia que não podia vê-los apenas como coitadinhos, mas, ao mesmo tempo, o tipo de relação mantido naquele momento não me deixava margens a interpretações alternativas.

\section{Manipulando identidades, superando armadilhas}

Algumas dessas inquietações começaram a ganhar sentido quando pude perceber que os caminhos que a pesquisa tomava não se deviam necessariamente a uma dificuldade pessoal de constituir outras vias de investigação. Devia-se ao fato de que aquela população que havia recortado - homens desempregados, assumidos como não trabalhadores e assim percebidos pelos demais - apresentava como característica marcante o consumo do álcool. A despeito de toda a diversidade desses homens, era central para grande parte deles essa referência e eram chamados pelos moradores do bairro de "papudinhos", um equivalente local para cachaceiro, bebum, pé de cana, pinguço em outras regiôes do Brasil. $\mathrm{O}$ fato de comungarem desemprego com bebida pareceria, em algum momento, como sendo uma dificuldade que instalaria um dilema para a análise da condição desses homens. Este recorte inviabilizaria a investigação? Refiro-me ao fato de que ao ser o alcoolismo reivindicado uma dependência química, esses homens deveriam ser vistos como doenteso que poderia dar rumos diferentes à pesquisa. ${ }^{8}$

Embora nem todos os homens que investiguei cumprissem esse perfil, tornou-se corriqueiro em um conjunto mais íntimo de colegas, referir-se a minha pesquisa como sendo "sobre"/"com" os papudinhos. Neste caso, quase como um sinônimo de homens pobres, desempregados, "sem poder" diante de outros homens e das mulheres, uma vez que não tinham dinheiro e, aparentemente nenhuma autoridade. Em outros momentos, essa designação acabou virando quase uma acusação ou uma forma de sugerir que aqueles não eram "representativos" do "homem real", o homem com dinheiro e poder que domina as mulheres. O meu recorte metodológico teria colocado em relevo um tipo marginal de masculinidade associado ao próprio modelo de análise com que eu estava operando.

Mesmo que vários autores tenham insistido que a "masculinidade hegemônica" é um "modelo ideal" que não é nunca atingido completamente na prática por homens concretos9 (Almeida, 1995), muitas vezes essa noção pode ser manuseada como se referindo a categorias estanques. Isso pode trazer duas consequências diretas. A primeira é que perdemos de vista que é no fluxo da ação que essas relações se definem. A segunda dificuldade, conforme mencionei, tem a ver com as manipulações possíveis a essas interpretaçôes, prestando-se facilmente a certo tipo de deslegitimação: “ah, são os papudinhos...". Considero que foi possível contornar esse dilema na medida em que outros elementos das trajetórias desses homens puderam ser trazidos à tona, de modo que o consumo de álcool, mesmo sendo uma dimensão central, foi considerado junto a outras, como, por exemplo: a) as diferentes relações mantidas; b) os discursos sobre a bebida e sobre a falta de trabalho; c) a alternância de momentos de bebida com momentos de abstinência; d) a manipulação da identidade de doentes. Elementos esses que permitiram não ver esses homens e as relações em que estavam inseridos como marcados apenas pela compaixão das pessoas que deles cuidavam (Nascimento, 2000).

O momento seguinte a essa opção foi a busca por perceber como esses homens legitimavam sua condição de serem percebidos como duplamente "dependentes": do álcool e de alguém que lhes sustentasse financeiramente. Agora se fazia necessário localizar os elementos que permitissem perceber, por trás daquela primeira nuvem de consternação, que aqueles homens não eram apenas pobres coitados, mas de algum modo procuravam gerir os processos de construção de suas identidades, que podiam ora sim, ora não, acionar a imagem de vítima.

Para levar a cabo essa proposta analítica foi necessário, inicialmente, relativizar o discurso do 
homem provedor ${ }^{10}$ como a principal atribuição masculina, a qual figurava como a primeira afirmação que faziam os homens quando procurei saber o que caracterizaria o padrão de masculinidade nessa comunidade (Nascimento, 1999). Apesar de os próprios homens ressaltarem a importância de ser trabalhador, uma vez configurada a condição do desemprego e sua abrangência naquela população, alguns homens que estavam sendo ou que já haviam sido "sustentados" por outra pessoa podem dar sentidos diversos a essa experiência, mesmo que ela continuasse sendo reivindicada como fundamental na definição das identidades masculinas. Nesse caso, o contexto da análise, como já dito, precisou incorporar a percepção do lugar da bebida na vida desses homens e o conjunto de relações que constituirão as redes nas quais eles, ao estarem inseridos, poderão através do discurso da enfermidade e/ou da falta de trabalho ou ainda pelo discurso da esperteza, de acordo com o interlocutor, forjar os meios de constituição do lugar que ocupam no seu círculo de relações e a imagem que manipulam.

Apenas depois de assim caracterizar essa população, é que eu poderia perceber como seriam (e se seriam) respondidas as perguntas que tinham sido postas inicialmente. Sem me dar conta, eu tinha me embrenhado em uma arena que agrupava dois universos de discurso - alcoolismo e desemprego que se, isoladamente, já eram difíceis de ser tratados, em conjunto tomavam, às vezes, a forma de uma armadilha, cuja associação é considerada muitas vezes como óbvia.

\section{Ser e não ser: a bebida para além de papudinhos}

Esta compreensão significa que a questão a ser considerada aqui é menos por que os homens bebem e mais perceber em que situaçôes a bebida passará a se configurar de modo negativo, e as diversas formas de lidar com seus efeitos, manipulando-os de modo distinto. Em termos nativos, a pergunta passa a ser: o que transforma um homem que bebe em um papudinho? E, para isso, notar como a relação com os demais membros da comunidade, bem como a forma como outros homens também bebedores são percebidos. Vejamos algumas dessas situações.

Daniel tinha 40 anos e era funcionário de um hospital público no Recife, cuja função era acompanhar pacientes em transporte na ambulância. A esposa de Daniel me disse em uma oportunidade: "esses dias mesmo eu tive que chamar a atenção dele, porque ele estava bebendo direto e queria faltar ao trabalho". Certa vez, Daniel estava em um dos bares do bairro tomando cerveja com um amigo que também era funcionário público. Ambos bebiam bastante nos dias de folga, fins de semana e na volta do trabalho à noite. Nesse episódio, os dois conversavam sobre as dificuldades de encontrarem um lugar onde pudessem beber sem serem molestados pelos papudinhos que sempre chegavam onde eles estavam e pediam bebida. Comentavam com desdém, buscando diferenciar-se, que não sabiam o que havia entre os papudinhos que viviam brigando, mas que "quando um tem um real pra comprar de cana já se chegam de novo".

Em outra ocasião, vi esse mesmo companheiro de Daniel no mesmo bar, comentando, com a voz embargada pelo álcool: "A coisa pior do mundo é esses homens que bebem até ficar caídos pelas ruas. Por isso, pode ser que eu chegue em casa e só dê tempo cair na cama, mas eu não vou ficar caindo pelas ruas não". Um outro ainda levantava a voz para os que estavam próximos ouvissem: "Homem que é homem tem que trabalhar. Porque um homem sem trabalho não é homem".

É possível dizer que é nessa tensão entre ser e não ser papudinho que esses homens se constituem enquanto homens e não homens. Antes de acompanharmos o caminho dessa construção, vejamos ainda mais alguns exemplos de como é muito mais difundida do que aparentemente se coloca a relação entre trabalho, não trabalho e bebida na vida dos homens - todos eles e não só os já identificados de forma negativa.

Conversando certa vez com Nilda, 35 anos, irmã de Paulo e Joca (dois irmãos vistos como $p a-$ pudinhos na comunidade) e esposa de Chico, um renomado pedreiro do bairro, ela falou que seu marido deveria trabalhar naquela segunda feira, mas por ter ido dormir muito tarde, não quis fazê-lo. Não diria que a percebi desapontada por isso ou, pelo menos demonstrando um grande estranhamento. Acredito que isso pode ser uma indicação 
de certo compartilhamento da visão apresentada por ele quando me disse, em outra ocasiáo, que agora não iria pegar mais trabalho "que exija muita responsabilidade", já que a esposa estava aposentada. É como se esta fosse uma possibilidade já considerada: ele ir ou não trabalhar.

Certa noite acompanhei Chico e Joca em uma incursão pela zona de prostituição do bairro, quando ouvi o primeiro dizer que sua esposa "não tinha porque se preocupar" porque ele já tinha deixado o dinheiro da feira. Durante um período em que Chico não estava bebendo, perguntei à sua mulher se não gostava que ele bebesse e o seu argumento foi referente exclusivamente à questão das implicaçôes da bebida para o uso do dinheiro e não a bebida em si ou potenciais malefícios a sua saúde.

Eu não gosto quando ele bebe porque ele gasta dinheiro demais. Ele não abusa comigo nem nada, mas o dinheiro não dá pra nada. Se ele bebe só no fim de semana não tem problema, mas tinha vez que ele começava a beber na quarta-feira e seguia bebendo todo dia, aí o dinheiro voava.

Joca, certa vez, falou longamente sobre seu cunhado e a relação dele com sua irmã e o trabalho:

Teve um tempo mesmo, quando a gente tava morando em Paudalho com ele, com mamãe ${ }^{11}$, de ele passar quase um ano parado. E a vida da gente era só pescar. Quando a gente chegava, tinha comida feita, tudinho. [Por que ele passou esse tempo parado?, eu perguntei.] Porque não aparecia serviço pra ele fazer e uma que ele já tava se acostumando porque, graças a Deus, mamãe já tava recebendo o dinheiro dela, aí mamãe fazia compra, tudinho. Faltava nada. Ou muito ou pouco a gente tinha dentro de casa, peixe, qualquer coisa, num faltava não. $\mathrm{E}$ assim a gente ia vivendo... Aí ele não se preocupava não de procurar emprego.

Ao compararmos essa narrativa, de um feliz e abundante passado, com o seguinte caso, será possível perceber algumas questōes. Bento, 38 anos, também bebia quase que diariamente, e há alguns anos bebia só nos fins de semana, segundo o dono do bar que ele frequentava mais regularmente. $\mathrm{O}$ comentário se deu em certo momento em que me disseram que Bento esteve doente por causa da bebida. Contudo, ele continuava trabalhando mesmo não tendo qualquer qualificação profissional que o diferenciasse dos demais. Há sete anos trabalhava fazendo bicos no mercado público de Camaragibe, entregando em casa feiras das pessoas que iam lá fazer compras. Tinha vários filhos todos pequenos e sua esposa não trabalhava fora de casa.

Daniel, Bento, Joca e Chico, dependendo de onde se observe, podem parecer muito aproximados ou muito diferenciados. Todos eles apresentaram momentos distintos em que, "por beberem demais", suscitaram preocupaçōes e acusaçōes daqueles com quem conviviam. Por outro lado, os contextos e as redes de apoio em que estavam inseridos davam-lhes condiçôes distintas de agenciamento e manipulação de suas identidades. Caso eu tivesse tido acesso às suas histórias em um momento ou outro apenas, talvez pudesse ter congelado suas experiências em um único ponto. $\mathrm{O}$ acompanhamento de suas trajetórias revelava particularidades que me impediam de fixar limites na forma como se identificariam e seriam caracterizados pelos seus pares.

Alguns homens que bebiam muito por determinado período, depois passavam "um tempo sem beber". Não era fácil configurar o que determinava uma "decisão" por esse tempo, sua duração e o que mudava de forma mais direta em suas vidas. Era um desafio passar a perceber o novo ritmo de vida de um abstêmio após meses de acompanhamento de sua bebida diária da mesma forma que não era simples reencontrar esse mesmo abstêmio embriagado em outro momento. Nesse percurso, procurar por identidades fixas no dia a dia do trabalho de campo poderia ser uma tarefa sem muito êxito. Para além dessas dificuldades, era possível perceber que, nesse período sem beber, mesmo frequentando os bares, começava-se a criar outro tipo de contato com o lar, onde a constante embriaguez se suspendia e talvez fosse possível aparecer de modo diferente frente os demais. ${ }^{12}$ Contudo, quer estivessem em fase de bebida ou de abstinência, os efeitos do consumo de álcool sobre a saúde e sobre a manutenção dos laços sociais eram percebidos com clareza pelos homens. Não só as dificuldades presentes no cotidiano, mas a noção de que problemas surgidos 
no passado estariam ligados à bebida e seus desdobramentos no presente.

Conversando com Renato, em um desses períodos em que ele não estava bebendo, ele falava sobre quando sofreu um acidente com o carro e as mudanças que ocorreram em sua vida: não arranjou mais emprego e passou dois anos sem trabalhar, bebendo. Disse que, nesse período, perdeu todos os documentos e ficou revoltado porque ninguém os devolveu. A partir daí não renovou mais a carteira de habilitação, que já estava vencida há vários anos. Justificava esta atitude dizendo que "não tem serviço" e, além de tudo, "os caras não confiam". Eu questionei, querendo demonstrar solidariedade, que o fato de ele ter sofrido um acidente não tinha a ver com não poder mais voltar a dirigir, mas ele retrucou dizendo saber-se culpado, pois, quando ocorreu o acidente, ele estava "cheio de cachaça".

A partir desse comentário, Renato começou a falar sobre "a cachaça" e o que pode causar a uma pessoa, retomando o que já me havia dito em tom sério de outra vez, que "a cachaça acaba com o cara". Falava sobre amigos que já haviam morrido por causa da bebida, ao mesmo tempo que citava seus próprios exemplos:

Quando eu tava bêbado, vindo do bar pra casa não via nada e esbarrava nas cercas, caía por cima dos arames, me arranhava todinho... Quando era no outro dia que me acordava tava todo cortado, mas pensa que eu parava? Começava tudo de novo... Já pensou? O cara se matar pelas próprias mãos. $\mathrm{E}$ o pior é que ainda às vezes nem morre depressa: fica doente sofrendo e aguentando piada dos outros. Tanto dos amigos quanto da família: "eu não mandei você beber?! Vá beber com seus amigos!”.

Dino, 39 anos (irmão de Renato), não bebia logo que o conheci. Quando retornei para a segunda fase de residência no bairro, cerca de um ano depois, ele era tido como um dos maiores bebedores e apontado por muitos como alguém que não viveria muito tempo se não parasse de beber, o que aconteceu um ano depois de encerrada a pesquisa. Da mesma forma, Brito, 40 anos, não somente reconhecia que estava doente à época da pesquisa em razão da bebida, como a continuação da mesma poderia levar ao abandono dele pela esposa. Em certo momento, em sua casa, perguntei se ele achava que havia muita diferença na forma da convivência com a esposa quando ele bebia e nos períodos em que não estava bebendo, e ele me disse: "Quando eu tô bebendo ela não fala comigo não... Quer nem conversa. Eu entro, saio, aí eu vou dormir. Mas agora não, agora eu parei de beber, já faz quatro meses. Ela tá boa demais!".

A bebida muitas vezes redundava em períodos de abstinência não apenas como uma forma de recobrar a possibilidade de continuar desfrutando do apoio e cuidado das mulheres com quem conviviam, mas também porque, diziam eles, eram "obrigados" a parar de beber por razōes de saúde. No entanto, quando a suspensão da bebida ocorria por esse motivo, a mesma se dava em virtude de hospitalização ou de casos mais graves de doenças decorrentes do consumo, como foi o caso do mesmo Brito que passou um longo período doente na casa da irmã, pois estava fazendo hemodiálise duas vezes por semana no Recife.

Em todo esse período em que estive em campo, apenas uma vez ouvi um dos homens falando que uma amiga sua o tinha sugerido ir a uma reunião dos Alcoólicos Anônimos. Esses períodos sem beber apareciam em suas vidas como parte de um esforço pessoal, muitas vezes sob pressão de amigos e familiares. Se isto está vinculado a outra forma de constituição e entendimento do que são os problemas que demandam atenção e está inserido num conjunto maior de privações, não foi este o foco deste trabalho. No entanto, não deverá passar despercebida a grande semelhança entre as representações formuladas por meus interlocutores com aquelas presentes em estudos realizados em instituiçôes como os Alcoólicos Anônimos, particularmente a noção de que a bebida pode levar à perda de controle e, assim, à impossibilidade de assumir responsabilidades sobretudo em relação à família e ao trabalho (Campos, 2004; Garcia, 2004). Por estar interessado muito mais no que as pessoas diziam sobre o consumo de álcool e como se relacionavam com o mesmo - não estabelecendo de forma radical seu uso enquanto positividade e problema -, certamente muitas questôes escaparam ao meu olhar. 
Manteve-se a perspectiva de ver ambos os lados como estando igualmente relacionados aos significados que aquelas pessoas davam para suas vidas e estes sendo construídos no seu dia a dia a partir das experiências com que se defrontavam. Isto impede qualquer tentativa generalizante de dizer como as pessoas se relacionariam com a questão, principalmente se estas análises se focarem em uma busca pelas razōes ou determinaçóes individuais para uma patologia e não nos caminhos pelos quais essas possibilidades se constituem socialmente, redundando ou não em doença.

\section{Comentários finais, ou saideira}

Além dessa insistência em pensar sobre a bebida e sua relação com o gênero a partir de uma perspectiva que levasse em conta os sentidos dados pelas pessoas a essas experiências, procurei refletir neste artigo, como esse exercício não esteve desvencilhado do próprio exercício da etnografia. As muitas questōes e objetivos que tinha em mente quando fui a campo em cada uma das etapas discutidas aqui foram, o tempo todo, postas sob suspeita. Refiro-me não apenas ao sentido de que existe um fluxo do dia a dia que em muito ultrapassa a nossa capacidade de fechá-lo em esquemas, mas o reconhecimento de que houve sempre a necessidade de questionar o meu lugar em campo, a minha relação com as pessoas com quem eu convivia e os pressupostos teóricos e políticos que geravam aquelas mesmas perguntas com as quais eu me deparava $\mathrm{e}$ as quais, algumas vezes, pensei em abandonar.

De todo modo, como enfatizei várias vezes, de forma mais central quis problematizar o desconforto com certas explicações que encaram a discussão sobre bebida e suas implicaçóes, entre elas, o alcoolismo, como sendo sempre decorrência de situações adversas, sendo o desemprego uma das principais. Esta explicação deixa de lado dois aspectos importantes: a forma como o consumo de álcool é um elemento nas configuraçôes de gênero e a diversidade de formas pelas quais os homens se inserem no mundo do trabalho e, assim, muitas vezes a expectativa de homem provedor não se atualiza (Nascimento, 2011). Essa visão do desemprego obscurece um conjunto gran- de da população que não vivencia a experiência do trabalho-emprego em sentido clássico.

Com isso, não nego nem a magnitude do alcoolismo como problema de saúde, nem a força da persistente e largamente partilhada expectativa de que o homem deve trabalhar e ser o provedor do lar. Chamo a atenção para o fato de que, enquanto estivermos olhando para fenômenos diferentes, marcados em suas especificidades, usando os mesmos instrumentos e os mesmos nomes para classificá-los, estaremos, talvez, distantes de vermos novas possibilidades de enfrentar velhos problemas.

\section{Notas}

1 Os estudos sobre masculinidades no Brasil, com o qual este trabalho dialoga, tem se ampliado significativamente, particularmente ao se cruzar com diversos campos como saúde, violência e sexualidade. Ver, por exemplo, Costa (2001), Machado (2003), Schraiber, Gomes e Couto (2005), Medrado e Lyra (2008), Toneli, Souza e Muller (2010), Gomes (2011) e Meinerz (2013).

2 É possível identificar no uso de álcool por mulheres a relação com questões de gênero, família e trabalho, como apontado por Campos e Reis (2010), embora focando um contexto diferente do abordado aqui.

3 Todos os nomes são fictícios.

4 Essa expressão da masculinidade não pode ser vista como algo restrito aos homens, como demonstrou Andrea Lacombe (2005) ao estudar modos de produção do masculino entre mulheres em um bar do Rio de Janeiro, fazendo parte de um campo de pesquisas em desenvolvimento, na qual se incluem, por exemplo, os estudos de Nádia Meinerz (2011) e Gilberta Soares (2014).

5 Sob esta definição, abordei um espectro por demais amplo de experiências e não me detive a uma definição formal de desemprego. No entanto, aqueles sujeitos, independente de qualquer atividade que viessem a desenvolver, não deixavam de ser percebidos e se perceberem como sujeitos desempregados, mesmo que em sua maioria nunca tivessem estado inseridos no mercado formal. Ver Nascimento (2011).

6 Também quando falo de "provedores" ou "não provedores", não estou acreditando que os contextos foram sempre recortados assim. Nem entendo como uma especificidade daquela comunidade, absolutizando conceitos e negando, por exemplo, o fato da variação do 
trabalho dos homens e a presença do trabalho fora de casa das mulheres pobres desde há muito tempo (e.g. Fonseca, 1997). Em outro exercício, também problematizei essa relação (Nascimento, 2005b, 2011).

7 Isto se relacionava a um debate, ainda persistente, sobre a oposição entre público e privado (Rosaldo, 1979, 1995). Para uma problematização, em contexto diferenciado, da separação estrita desses domínios e da consequente reificação da imagem do homem ausente, ver Longhi (2001).

8 O que implicaria concordar com um destacado estudioso da saúde coletiva que certa vez afirmou, ao debater outro trabalho de minha autoria, que "a antropologia não deveria se preocupar com o alcoolismo" (Nascimento, 2005a).

9 E foi com esta perspectiva que desenvolvi as pesquisas aqui discutidas.

10 Como já havia feito, por exemplo, Alba Zaluar (1995), ao demonstrar que essa atribuição não era exclusividade dos homens.

11 Dona Aline, a única mulher que vi beber e se embriagar junto aos homens - mãe de Joca, Paulo e Nilda - ocupava uma posição de destaque que, talvez, lhe permitisse lugares e performances interditadas a outras mulheres ou não desejadas por elas. Viúva e recebendo uma gorda pensão, para os padrões locais, do seu falecido marido funcionário público, era ela quem, além de "sustentar" os filhos e frequentemente ajudar nas despesas da casa de sua filha, pagava "por mês" no bar as altas contas do que bebia com seus colegas homens, entre eles, seus dois filhos e o genro.

12 Ver Gutmann (1996), para a mesma reflexão sobre abstinência e estar jurado.

\section{BIBLIOGRAFIA}

ALMEIDA, Miguel Vale de. (1995), Senhores de si: uma interpretação antropológica da masculinidade. Lisboa, Fim de Século.

BERRIDGE, Virginia. (1994), "Dependência: história dos conceitos e teorias", in G. Edwards e M. Lader (orgs.), A natureza da dependência de drogas. Porto Alegre, Artes Médicas.

BONETTI, Alinne \& FLEISCHER, Soraya. (2007), Entre saias justas e jogos de cintura. Florianópolis/Santa Cruz do Sul, Unisc/ Editora Mulheres.
BRANDES, Stanley. (2003), "Drink, abstinence, and male identity in Mexico City", in M. Gutmann (ed.), Changing men and masculinities in Latin America. Durham, Duke University Press.

BUTLER, Judith. (2003), Problemas de gênero. Rio de Janeiro, Civilização Brasileira.

CAMPOS, Edemilson Antunes de. (2004), "As representaçóes sobre o alcoolismo em uma associação de ex-bebedores: os Alcoólicos Anônimos”. Cadernos de Saúde Pública, Rio de Janeiro, 20 (5): 1379-1387. Disponível em: <http://www.scielo.br/scielo.php?script=sci_ arttext\&pid=S0102-311X2004000500033\&l $\mathrm{ng}=\mathrm{pt} \& \mathrm{nrm}=\mathrm{iso}>$. Acesso em: 25 jul. 2015.

CAMPOS, Edemilson Antunes de \& REIS, Jéssica Gallante. (2010), "Representações sobre o uso de álcool por mulheres em tratamento em um centro de referência da cidade de São Paulo - Brasil”. Interface, Botucatu, 14 (34): 539-550. Disponível em: <http://www.scielo. br/scielo.php?script=sci_arttext\&pid=S1414$-32832010000300006 \& \operatorname{lng}=p t \& n r m=$ iso $>$. Acesso em: 25 jul. 2015.

CLIFFORD, James. (1998), "Sobre a autoridade etnográfica”, in _. A experiência etnográfica. Antropologia e literatura no século XX. Rio de Janeiro, Editora da UFRJ.

CONNELL, R. (1997), "La organización social de la masculinidad", in T. Valdés e J. Olavarría (eds.), Masculidadles: poder e crisis, Santiago, Chile: Ediciones de las Mujeres, vol. 24.

COSTA, Rosely Gomes. (2001), Concepção de filhos, concepçôes de pai: algumas reflexões sobre reprodução e gênero. Tese de doutorado em Ciências Sociais. Campinas, Unicamp.

FAVRET-SAADA, Jeane. (2005), "Ser afetado". Tradução de Paula de Siqueira Lopes. Cadernos de Campo, São Paulo, 13: 155-161. Disponível em: <http://www.revistas.usp.br/cadernosdecampo/article/viewFile/50263/54376>. Acesso em: 14 fev. 2016.

FONSECA, Claudia. (1997), "Ser mulher, mãe e pobre”, in M. Del Priore (org.), História das mulheres no Brasil, São Paulo, Contexto, pp. 510-553.

. (2000), "A importância do olhar etnográfico", in Familia, fofoca e honra: etno- 
grafia de relaçôes de gênero e violência em grupos populares, Porto Alegre, Editora da UFRGS.

GARCIA, Ângela Maria. (2004), E o verbo (re)fez o homem: estudo do processo de conversão do alcoólico ativo em alcoólico passivo. Niterói: Intertexto.

GEERTZ, Clifford. (1989), A interpretação das culturas. Rio de Janeiro, Guanabara.

. (2002), Vidas e obras: o antropólogo como autor. Rio de Janeiro, Editora da UFRJ.

GOMES, Romeu (org.). (2011), Saúde do homem em debate. Rio de Janeiro, Editora Fiocruz.

GUEDES, Simoni. (1997), Jogo de corpo: um estudo de construção social de trabalhadores. Niterói, EDUFF.

GUTMANN, Matthew. (1996), "Degendering alcohol", in The meanings of macho: being a man in Mexico City, Berkeley, University of California Press.

JARDIM, Denise. (1991), De bar em bar: identidade masculina e autossegregação entre homens de classes populares. Dissertação de mestrado em antropologia social, Porto Alegre, Universidade Federal do Rio Grande do Sul.

LACOMBE, Andrea. (2005), "Pra homem já tô eu": masculinidades e sociabilidades lésbicas em um bar do centro do Rio de Janeiro. Dissertação de mestrado em antropologia social. Rio de Janeiro, UFRJ.

LEAL, Ondina F. \& BOFF, Adriane. (1996), "Insultos, queixas, sedução e sexualidade: fragmentos de identidade masculina em uma perspectiva relacional", in R. Parker e R. Barbosa (orgs.), Sexualidades brasileiras, Rio de Janeiro, Relume Dumará.

LONGHI, Márcia. (2001), Ser homem, pobre e pai. Dissertação de mestrado em antropologia cultural. Recife, Universidade Federal de Pernambuco.

MACHADO, Paula Sandrine. (2003), Muitos pesos e muitas medidas: um estudo antropológico sobre as representaçôes masculinas na esfera das decisöes sexuais e reprodutivas. Dissertação de mestrado em antropologia social. Porto Alegre, UFRGS.

MACHADO DA SILVA, Luiz Antônio. (1978), "O significado do botequim", in L. Kowarick. Cidade: usos \& abusos, São Paulo, Brasiliense.

MATOS, Maria Izilda dos Santos de. (2001), Meu lar é o botequim: alcoolismo e masculinidade.
São Paulo, Companhia Editora Nacional. MEDRADO, Benedito \& LYRA, Jorge. (2008), "Por uma matriz feminista de gênero para os estudos sobre homens e masculinidades". Revista de Estudos Feministas, Florianópolis, 16 (3): 809-840. Disponível em: <http://www.scielo. br/scielo.php?script=sci_arttext\&pid=S0104-026X2008000300005\&lng=pt\&nrm=iso $>$. Acesso em: 25 jul. 2015.

MEINERZ, Nádia Elisa. (2011), Mulheres e masculinidade: etnografia sobre afinidades de gênero no contexto da parceria homoerótica feminina em grupos populares. Tese de doutorado em antropologia social. Porto Alegre, UFRGS.

. (2013), "Se essas paredes pudessem falar". Bagoas, 10: 55-72. Disponível em: <http:// www.periodicos.ufrn.br/bagoas/article/ view/5375/4390>. Acesso em: 14 fev. 2016.

NASCIMENTO, Pedro. (1995), "Mulher é o cão": a construção da identidade masculina em bar da feira central de Campina Grande/PB. Monografia para o bacharelado em Ciências Sociais. Campina Grande, Universidade Federal da Paraíba.

(1999), "Ser homem ou nada": diversidade de experiências e estratégias de atualização da masculinidade hegemônica em Camaragibe/PE. Dissertação de mestrado em antropologia cultural. Recife, Universidade Federal de Pernambuco.

. (2000), "Homens pobres, masculinidades à margem: a construção social da masculinidade em Camaragibe/PE" Relatório de Pesquisa - Prodir III. São Paulo, Fundação Carlos Chagas/Fundação MacArthur.

(2005a), "O gênero do alcoolismo: reflexões a partir da sociabilidade masculina e desemprego". Trabalho apresentado no III Congresso Brasileiro de Ciências Sociais e Humanas em Saúde, Florianópolis, Abrasco/UFSC.

. (2005b), "Homens desempregados, mulheres provedoras: qual a novidade?". Trabalho apresentado na VI Reunião de Antropologia do Mercosul, Montevideo, Faculdad de Humanidades/Universidad de la Republica.

(2011), "Não provedores: homens, mulheres e desemprego em uma 'Invasão' em Camaragibe/ PE", in P. Nascimento e L. F. Rios (orgs.), Gênero, saúde e práticas profissionais, Recife, Ed. UFPE. 
NEVES, Delma P. (2003), "O consumo de bebidas alcoólicas: prescriçōes sociais”. BIB - Revista Brasileira de Informação Bibliográfica em Ciências Sociais, 55: 73-97. . (2004), "Alcoolismo: acusação ou diagnóstico?”. Cadernos de Saúde Pública, 20 (1): 7-14.

ROSALDO, Michelle Z. (1979), "A mulher, a cultura e a sociedade: uma revisão teórica", in $\mathrm{M}$. Z. Rosaldo e L. Lamphere (coords.), A mulher, a cultura e a sociedade, Rio de Janeiro, Paz e Terra. . (1995), "O uso e o abuso da antropologia: reflexôes sobre o feminismo e o entendimento intercultural”. Horizontes Antropológicos, 1 (1): 11-36.

SARTI, Cynthia. (1996), A familia com espelho: estudo sobre a moral dos pobres. São Paulo, Autores Associados.

SCOTT, R. Parry. (1990), "O homem na matrifocalidade: gênero, percepção e experiências do domínio doméstico". Cadernos de Pesquisa, 73: 38-47.

SCHRAIBER, Lília Blima; GOMES, Romeu \& COUTO, Márcia Thereza. (2005), "Homens e saúde na pauta da Saúde Coletiva”. Ciência e Saúde Coletiva, 10 (1): 7-17. Disponível em: $<$ http://www.scielo.br/scielo.php?script=sci arttext\&pid=S1413-81232005000100002\&ln $\mathrm{g}=\mathrm{pt} \& \mathrm{nrm}=\mathrm{iso}>$. Acesso em: 25 jul. 2015.

SOARES, Gilberta Santos. (2014), Sapatos tem sexo? Metáforas de gênero em lésbicas de baixa renda, negras, no nordeste do Brasil. Tese de doutorado em estudos interdisciplinares sobre mulheres, gênero e feminismos. Salvador, UFBA.

TONELI, Maria Juracy Filgueiras; SOUZA, Marina Gomes Coelho de \& MULLER, Rita de C. Flores. (2010), "Masculinidades e práticas de saúde: retratos da experiência de pesquisa em Florianópolis/SC". Physis, 20 (3): 973994. Disponível em <http://www.scielo.br/ scielo.php?script $=$ sci_arttext \&pid $=$ S0103$-73312010000300015 \& \operatorname{lng}=$ pt\&nrm $=$ iso $>$. Acesso em: 25 jul. 2015.

VALDÉS, Teresa \& OLAVARRÍA, José. (eds.) (1998), Masculinidades y equidad de género en América Latina, Santiago, Chile, Flacso.

ZALUAR, Alba. (1995), A máquina e a revolta. São Paulo, Brasiliense. 


\section{BEBER COMO UM HOMEM: DILEMAS E ARMADILHAS EM ETNOGRAFIAS SOBRE GÊNERO E MASCULINIDADES}

\section{Pedro Nascimento}

Palavras-chave: Etnografia; Consumo de álcool; Gênero; Masculinidades; Homens.

Este artigo apresenta a trajetória de pesquisas etnográficas sobre gênero e masculinidades, destacando as vicissitudes desse objeto de pesquisa em seu cruzamento com a questão do consumo de bebidas alcoólicas. Destaca-se a contribuição da pesquisa etnográfica para o campo de estudos sobre o consumo de bebida alcoólica, evitando uma abordagem medicalizada e moralizante da questão e sua imediata relação com o alcoolismo. Para isso, são considerados os significados socialmente compartilhados sobre o ato social de beber; os elementos do trabalho e da conjugalidade, bem como a rede de relações mais ampla em que os sujeitos estão inseridos. Essa abordagem torna-se importante para compreender como esses sujeitos não podem ser vistos simplesmente como dependentes ou doentes e as formas como múltiplas identidades são negociadas.

\section{DRINKING LIKE A MAN: DILEMMAS AND PITFALLS IN GENDER ETHNOGRAPHIES, MASCULINITY}

\section{Pedro Nascimento}

Keywords: Ethnography; Alcohol consumption; Gender; Masculinity; Men.

This article presents the trajectory of the recent ethnographic research on gender and masculinity highlighting the unfolding of the theme in its crossing with the issue of alcohol consumption. It deals with the contribution of the ethnographic research to the study of alcohol consumption, so avoiding a biomedical and moralizing approach to the issue and its immediate link with alcoholism. In this sense, the article considers the socially shared meanings about the social act of drinking, as well as the elements involved in work and conjugality, and the wider network of relations in which the actors are embedded. Such approach proves to be important in order to understand how the concerned persons cannot be seen simply as dependents or ill, and the ways in which multiple identities are negotiated.

\section{BOIRE COMME UN HOMME: DILEMMES ET PIÈGES DANS UNE ETHNOGRAPHIE SUR LE GENRE, LES MASCULINITÉS}

\section{Pedro Nascimento}

Mots-clés: Ethnographie; Consommation d'alcool; Genre; Masculinités; Hommes.

Cet article présente le parcours des recherches ethnographiques à propos du genre et des masculinités en mettant en avant les vicissitudes de cet objet de recherche par rapport à la consommation de boissons alcooliques. L'article met en avant la contribution de la recherche ethnographique dans le domaine d'études à propos de la consommation d'alcool tout en évitant une approche médicalisée, voire moralisée, de cette question et sa relation immédiate avec l'alcoolisme. Il considère ainsi les définitions partagés socialement à propos de l'acte social de boire ; les éléments du travail et de la conjugalité, ainsi que le vaste réseau des relations dans lesquelles les sujets sont insérés. Cet abordage est important en vue de comprendre la raison par laquelle ces sujets ne peuvent être simplement considérés comme des dépendants ou des malades. Il permet aussi de comprendre les formes par lesquelles les identités multiples sont négociées. 